\title{
Cierre de la brecha digital: mecanismos de priorización para el despliegue y posibilidades para las redes comunitarias
}

Revista Latinoamericana de Economía y Sociedad Digital

Issue 1 , agosto 2020

Autores: Ana Gabriela Valdiviezo Black, Ramiro Valencia Barahona

DOI: $10.53857 / \mathrm{XOQY} 3100$

Publicado: 10 agosto, 2020

Cita sugerida: Valdiviezo Black, Ana Gabriela \& Valencia Barahona, Ramiro (2020) "Cierre de la brecha digital: mecanismos de priorización para el despliegue y posibilidades para las redes comunitarias" en Revista Latinoamericana de Economía y Sociedad Digital, Issue 1

Licencia: Creative Commons Atribución-NoComercial 4.0 Internacional (CC BY-NC 4.0)

Tipo: Estudio de caso

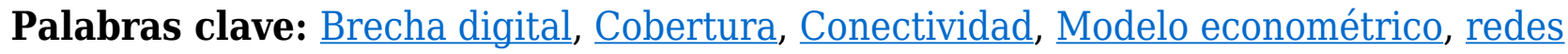
comunitarias, Regulación, Servicio móvil

\section{Resumen}

Los gobiernos de los países han intentado disminuir la brecha de conectividad y acceso a servicios TIC a través de proyectos como telecentros comunitarios o políticas de obligaciones de cobertura a prestadores de servicios, sin lograr resultados eficientes.

Esta investigación realiza un análisis de la brecha y un modelo econométrico para conocer los parámetros influyentes en el porcentaje de cobertura de servicio móvil e Internet, y plantea una priorización de zonas geográficas no cubiertas actualmente en Ecuador. La metodología aplicada tiene por hipótesis que, a partir de mayor presencia de nodos e infocentros con fibra óptica en la parroquia a cubrir, será más rápido el despliegue de infraestructura y la adopción de los servicios.

A partir de la priorización, se plantea un análisis regulatorio para fomentar la conectividad a través del esquema de red comunitaria o red de uso social. 


\section{Introducción}

La brecha digital, en los diferentes niveles, refiere a la relación en el acceso, uso o habilidades de las personas de determinados grupos sociodemográficos, concernientes a las tecnologías de la información y la comunicación (TIC). La perspectiva de la desigualdad digital se puede establecer desde diferentes aristas como la geográfica, de género, de asequibilidad, entre otras. De igual manera, es importante analizar los indicadores clave que permiten distinguir la probabilidad de poseer un mayor y mejor acceso en términos de calidad o de capacidad.

Si nos preguntamos cuáles son las cualidades de cierta población para tener acceso frente a otra, enseguida las respuestas cualitativas pueden darse a partir de su localización, capacidad económica, cantidad de habitantes, región de vivienda, entre otras; pero el análisis de su magnitud podría darnos una mejor orientación sobre las estrategias de conectividad que pueden surgir. Es decir, no todas las localidades pueden o deben tener el mismo componente estratégico para su ampliación de cobertura o implementación de asequibilidad en su acceso.

En Ecuador, según cifras obtenidas a partir de la Encuesta Multipropósito del Instituto Ecuatoriano de Estadísticas y Censos (INEC), al año 2018, el porcentaje de personas que tienen un teléfono celular activo asciende al 59 \% a nivel nacional; es decir, que 6 de cada 10 ecuatorianos tiene una línea móvil activa, aunque la penetración del servicio móvil publicada por la Agencia de Regulación y Control de las Telecomunicaciones (ARCOTEL) es del $92 \%$, lo cual muestra una diferencia nacional de 33 \%. Pero si estas cifras se analizan a nivel geográfico urbano y rural, el primer grupo presenta 65,2 \% de tenencia; mientras que el segundo, un $46 \%$, consolidando una brecha de casi 20 personas por cada 100 habitantes más que poseen un teléfono activo en las zonas urbanas frente a las localidades rurales. Tendencias similares se muestran en lo que concierne a Internet, ya que a nivel nacional el $55,9 \%$ lo han usado. A nivel urbano se registra un 64,4 \% y en la zona rural, un 37,9 \%, lo cual representa una brecha de 26 de cada 100 personas más que usan Internet en zonas urbanas frente a las zonas rurales.

Con las mismas fuentes de información, si este mismo ejercicio es reproducido sobre la base del género, se puede notar que ha existido un crecimiento de 20,7 \% en el uso de Internet en la mujer entre 2012-2018, pero la brecha a nivel nacional sigue siendo casi igual que hace 6 años (2\%); y, aun cuando, en el global, la brecha de tenencia de celular entre el mismo periodo se redujo 1,5\%, solo entre 2017 y 2018, esta aumentó 1,7 \%. En general, se nota un crecimiento en los indicadores agregados y una mejoría en lo que respecta a los niveles de desigualdad entre 2012 y 2018, pero a partir del año 2015, esas diferencias han empezado a incrementarse gradualmente. En ese sentido, podrían caber dos preguntas para analizar dichas tendencias: ¿̇los efectos de la recesión económica que empezó a sufrir el país a partir de 2015 influyeron sobre la expansión de los servicios de telecomunicaciones? ¿La política pública está realmente ayudando a cubrir las brechas de acceso a y uso de la 
información por medio de las TIC de forma eficiente?

En Ecuador existen 1024 parroquias urbanas y rurales, que tienen como determinante el porcentaje de cobertura poblacional móvil y el nivel de penetración de Internet fijo en función de la densidad poblacional, la infraestructura desplegada, características geográficas, demográficas, entre otras, que permiten conocer que el principal factor para acceder a un servicio es la capacidad adquisitiva. Por otra parte, la falta de infraestructura también corresponde a un factor influyente en el acceso a y uso del servicio. El modelo propuesto, representado a través de una regresión multivariante, utiliza un corte de información de la cobertura poblacional del servicio móvil (oferta) en las parroquias como variable dependiente, frente al nivel de necesidades básicas insatisfechas y las características geográficas de la localidad, de lo cual se obtiene que existe mayor cobertura en la zonas urbanas. Además, mientras mejores sean las condiciones básicas de la parroquia, sus coeficientes indican una mejor probabilidad de que más cantidad de sus habitantes posean un servicio de telecomunicaciones.

De este estudio también se desprende que, para el periodo de análisis (2018), existen 392 parroquias sin cobertura de servicios móviles $\left(2 \mathrm{G}, 3 \mathrm{G}\right.$ o 4G) ${ }^{[1]}$, con 214 parroquias que tampoco tienen acceso a servicios de Internet fijo. Por su parte, existen 857 parroquias sin cobertura 4G; aunque al menos 154 parroquias con estas características poseen un infocentro comunitario provisto con fibra óptica como medio de acceso.

De esta manera, se aplica otro modelo, con criterios de infraestructura disponible en las localidades en cuestión como variable dependiente, que tiene por hipótesis que a partir de mayor presencia de nodos e infocentros con fibra óptica cercanos a la parroquia para cubrir con servicios, será más rápida la instalación de infraestructura necesaria para alcanzar a los hogares de estos sitios. El modelo también busca describir cómo influye la cantidad de escuelas y centros de salud, así como el porcentaje de "no pobres", medido por el factor de necesidades básicas insatisfechas (NBI), que tiene cada parroquia sobre la cantidad de sitios (nodos e infocentros con fibra) que actualmente están dispuestos en las cercanías de dichas localidades, con la finalidad de cumplir la hipótesis planteada.

En ese sentido, y considerando el auge de las redes comunitarias o redes de uso social compartido, se pone de manifiesto la necesidad de las propias localidades sin servicios de obtener el acceso a la información a través de las TIC. Es importante notar que esta necesidad responde principalmente a la falta de operadores establecidos o de mecanismos de ejecución de fondos o inversión pública que permitan generar sostenibilidad de los proyectos de conectividad rural en el tiempo. De esta manera, es necesario revisar cuáles son las aristas regulatorias que el país contiene o le hacen falta, con la finalidad de impulsar revisiones normativas para el fomento de este tipo de redes que pueden funcionar para la autodotación o autogestión de cualquier servicio de telecomunicaciones.

Con el resultado de la investigación se pretende generar un modelo aplicable, incluso a la realidad de cualquier país, y escalable en cuanto a la información disponible y los aspectos 
de política que cada Estado pretenda realizar; de forma que se puedan construir planes de conectividad que impulsen el cierre de la brecha digital y la promoción de la tecnología en sectores transversales como salud y educación en las poblaciones alejadas.

\section{Análisis de la brecha digital en Ecuador}

La brecha digital principalmente existe por el lado del consumo de los servicios ${ }^{[2]}$; por lo que la otra paradoja que se plantea es cómo diseñar esas estrategias de conectividad si los operadores establecidos generalmente no implementan sus redes en sitios donde el consumo no representa un retorno sobre su inversión. En ese sentido, la alternativa intuitiva más viable para proveer la conectividad en zonas alejadas terminan por ser los fondos de servicio universal, inversión a través de empresas públicas o inversión pública en proyectos sociales; pero, con habitualidad, estos proyectos adolecen de la continuidad necesaria o del enfoque adecuado para su sostenibilidad, ya sea por falta de presupuesto o por falta de reglas claras para su implementación.

La brecha desde la demanda o consumo se refiere al potencial grupo de personas que, teniendo la cobertura de la red, no acceden al servicio, lo que puede suceder por la falta de poder adquisitivo de los bienes o servicios necesarios, desinterés en la tecnología y falta de habilidades para su uso. La brecha de oferta alude a las personas que, teniendo la posibilidad de acceder al servicio, no lo pueden hacer por dos aspectos: falta de cobertura (infraestructura) o escasez de planes comerciales que no se ajustan a la expectativa de la demanda potencial.

Figura 1. Representación de la oferta y demanda de los servicios de telecomunicaciones

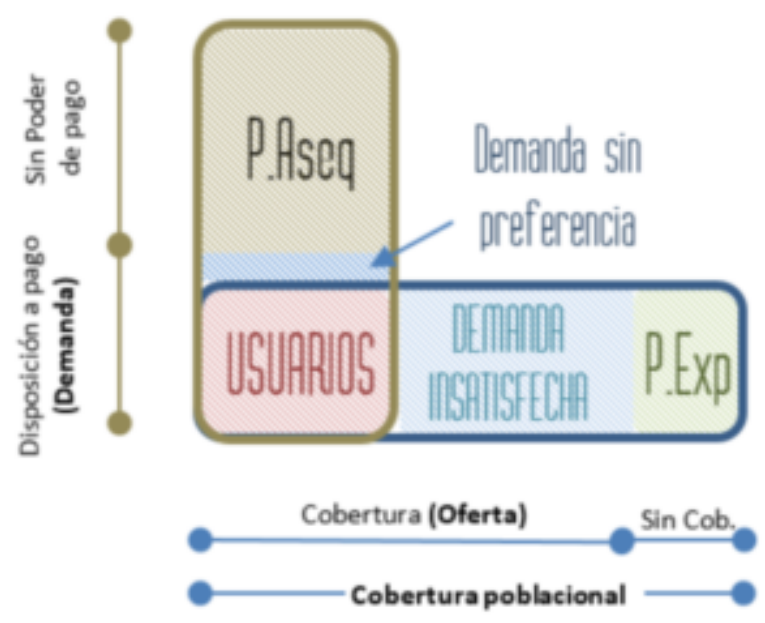

Fuente: Valencia, Ramiro. 2017. CPR - Vol.12 
La brecha tiene muchos componentes tanto sociales como económicos, que pueden analizarse para los servicios e incluso las facilidades de uso y aprendizaje en la tecnología. Se podría decir que las más conocidas dentro de la expansión de los servicios son las siguientes: geográficas (urbano-rural), de género (masculino-femenino), regional (sierra, costa, oriente, insular), económico (entre quintiles), generacional (etario), étnica (negros, indios, mestizos, blancos), entre otras. Tomando en cuenta esta categorización, se puede intuir que los beneficios que pueden generar el acceso y el uso de las TIC tampoco se encuentran distribuidos y constituyen "nuevos factores de desigualdad, que reproducen distinciones ya encontradas en las sociedades y por lo tanto se exacerban las diferencias en el acceso por parte de los distintos grupos sociales" (Castells 2006). Pero resulta necesario indicar que las tecnologías no amplían dichas desigualdades por sí mismas, ya que, como argumenta Castells, estas se generan por la posibilidad de acceder a la información que se cursa por esta red (Valencia 2017).

A continuación analizaremos las dos primeras brechas para el caso ecuatoriano.

\subsection{Brecha geográfica urbano-rural}

\subsubsection{Brecha de tenencia de celular activo}

En la siguiente figura se puede apreciar que la brecha geográfica, en lo que concierne a la tenencia de teléfono celular activo, en el periodo 2012-2018, ha ido reduciéndose hasta el año 2014 y, posterior a ello, se puede notar un constante aumento.

El crecimiento de la tenencia, en dicho periodo, para el grupo urbano es de 7,6 \%, lo cual incluso es menor con respecto al grupo rural, que representa un 9,8\%, pero la diferencia interanual en cada grupo hace notar que las zonas rurales no han tenido una tasa de variación constante de penetración como lo muestra la parte urbana.

Figura 2. Brecha de demanda geográfica y crecimiento interanual acumulado para la tenencia de un celular activo
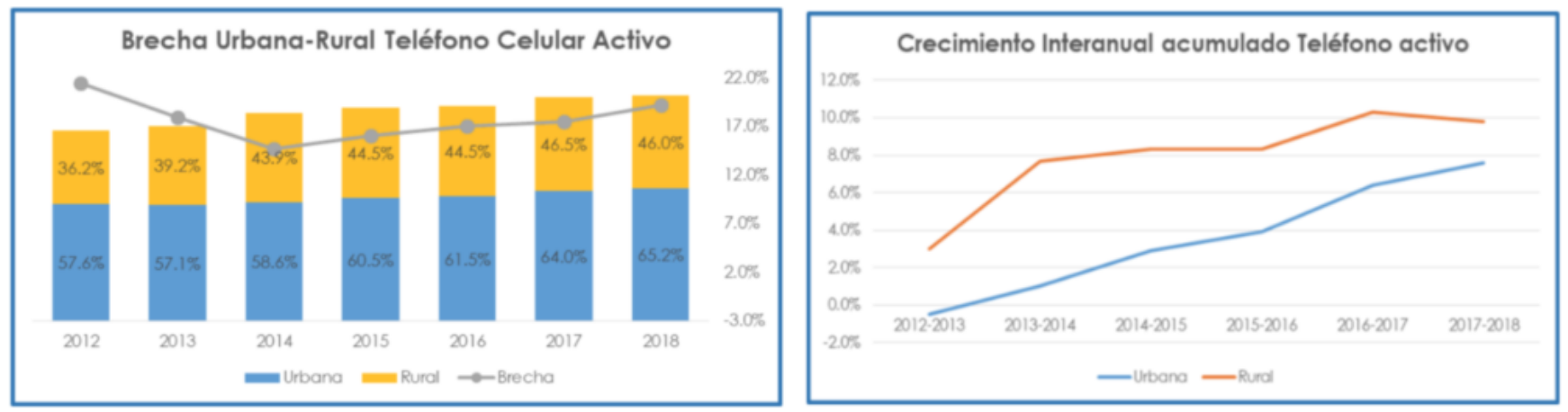

Fuente: INEC 2012-2018, Encuesta ENEMDU-TIC, elaboración propia. 


\subsubsection{Brecha de uso de Internet}

Para el uso de Internet, se nota que la brecha geográfica, en el periodo 2012-2018, ha ido reduciéndose hasta el año 2014 y, en lo posterior, se observa un crecimiento que incluso llega a ser mayor en el año 2018 con relación al 2012.

El aumento, en dicho periodo, para el grupo urbano es de 20,5\% y, en la zona rural, de $20,1 \%$, aunque la diferencia interanual del grupo urbano ha tenido mejor desempeño en la densidad del servicio.

Figura 3. Brecha de demanda geográfica y crecimiento interanual acumulado para el uso de Internet
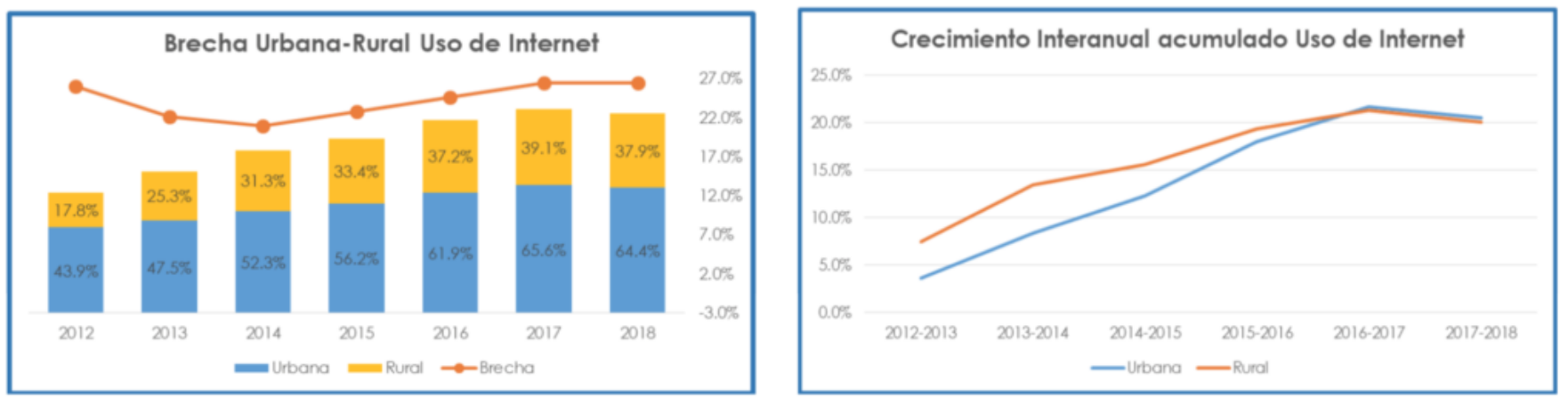

Fuente: INEC 2012-2018, Encuesta ENEMDU-TIC, elaboración propia.

\subsubsection{Brecha de analfabetismo digital}

Para el caso del analfabetismo digital por zonas geográficas, se nota que la brecha, en similares periodos, ha ido reduciéndose hasta el año 2018; es decir, que se podría inferir que, a pesar de notar una brecha importante en el acceso efectivo a las TIC, existiría un decrecimiento en la brecha de conocimiento y uso de las TIC en las zonas rurales debido a proyectos de alistamiento digital ${ }^{[3]}$ implementados por el Estado, lo cual puede notarse en la tasa de decrecimiento del analfabetismo digital en las zonas rurales con relación a las zonas urbanas en el gráfico de crecimiento interanual acumulado.

Figura 4. Brecha de demanda geográfica y crecimiento interanual acumulado para la métrica de analfabetismo digital 

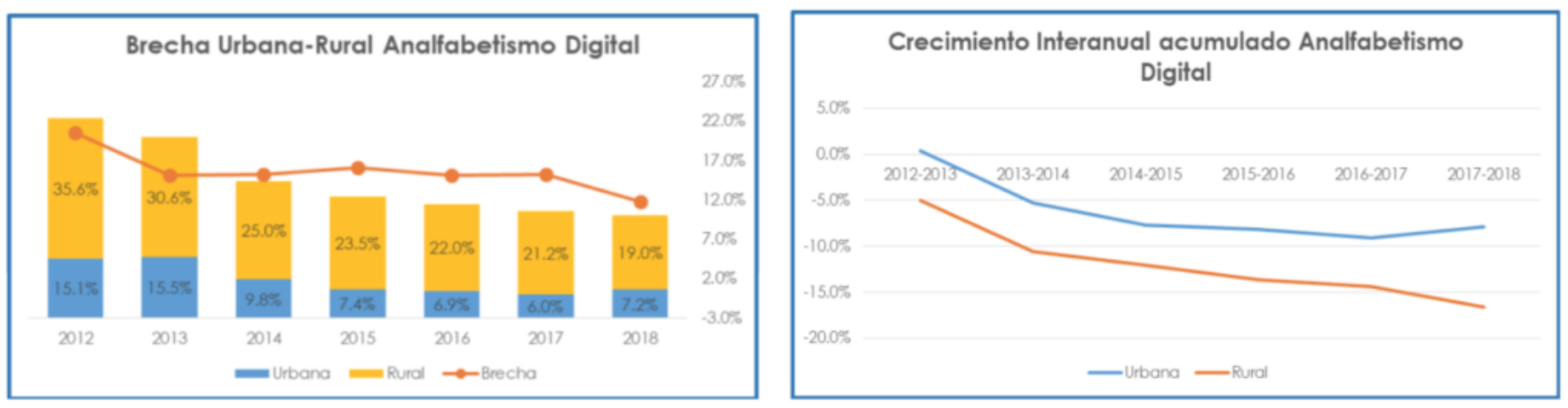

Fuente: INEC 2012-2018, Encuesta ENEMDU-TIC, elaboración propia.

\subsection{Brecha de género}

\subsubsection{Brecha de tenencia de celular activo}

Con relación a la tenencia de un celular activo, se puede notar que la brecha ha tenido una reducción hasta el año 2018 de aproximadamente 1,5 \%, así como que en el último año ha existido un crecimiento de 1,7 \%. Aunque el mayor crecimiento, desde el año 2012, se presenta para la mujer, la tasa de crecimiento es constante para el hombre en el periodo de estudio.

\section{Figura 5. Brecha de demanda de género y crecimiento interanual acumulado para la tenencia de celular activo}
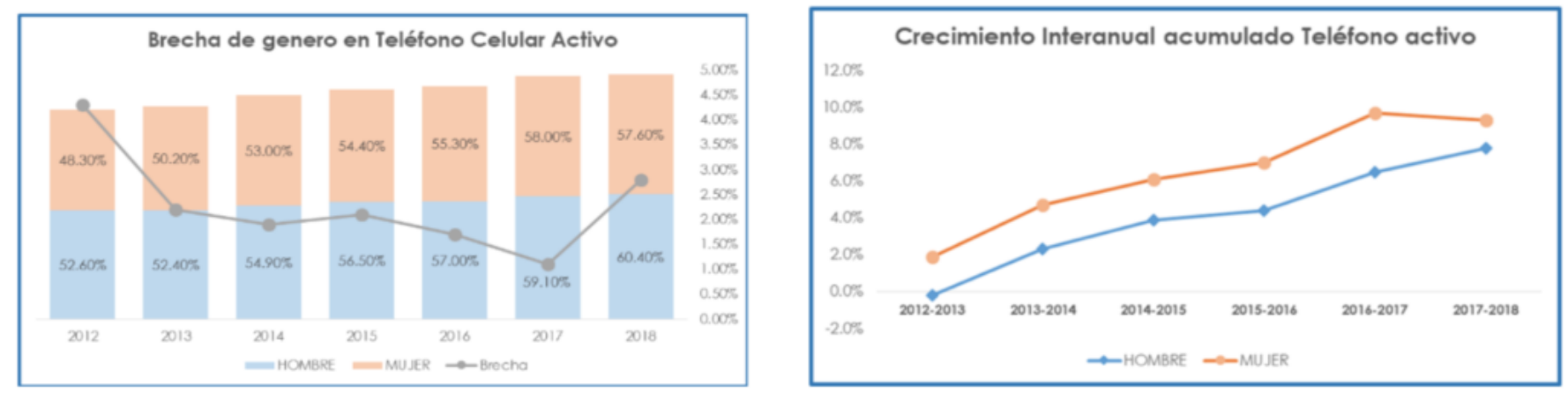

Fuente: INEC 2012-2018, Encuesta ENEMDU-TIC, elaboración propia.

\subsubsection{Brecha de uso de Internet}

Con respecto al crecimiento en el uso de Internet en la mujer entre 2012-2018, se puede apreciar un 20,7 \% más, pero a partir del año 2016 se nota un incremento en la brecha, la cual, actualmente, sigue siendo casi igual que hace 6 años.

Figura 6. Brecha de demanda de género y crecimiento interanual acumulado para el uso de 
Internet
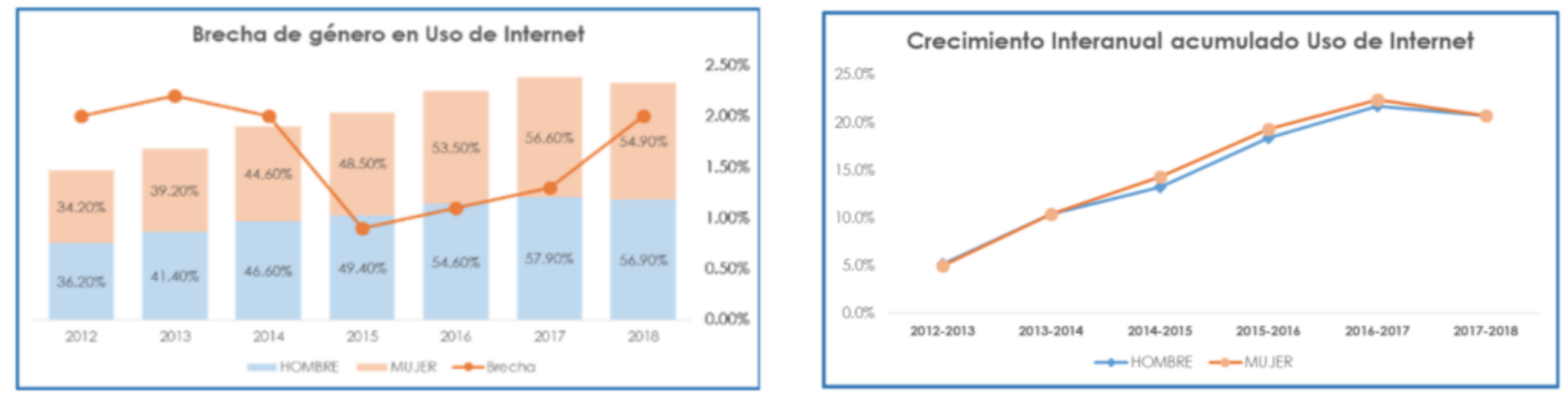

Fuente: INEC 2012-2018, Encuesta ENEMDU-TIC, elaboración propia.

\subsubsection{Brecha de analfabetismo digital}

Para el caso del analfabetismo digital, se puede observar que la brecha, en el periodo de estudio, se ha ido reduciendo hasta el año 2018. Si vinculamos este análisis con el similar de la brecha geográfica, se podría colegir que, aunque existe un crecimiento en la brecha de acceso a celular e Internet, se nota que el uso de las TIC en el género femenino ha tenido un incremento sostenido.

Figura 7. Brecha de demanda de género y crecimiento interanual acumulado para la métrica de analfabetismo digital
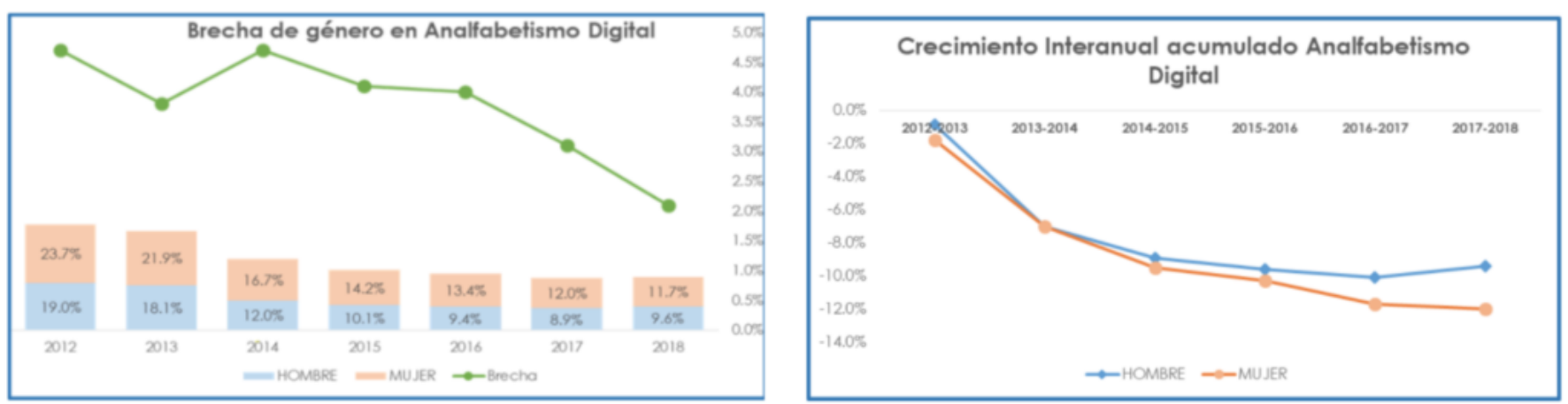

Fuente: INEC 2012-2018, Encuesta ENEMDU-TIC, elaboración propia.

\subsection{Brecha digital en el contexto de la crisis sanitaria por COVID-19}

La necesidad de acortar la brecha digital se vuelve cada vez más imperiosa. Durante estos últimos meses, el mundo entero ha sido testigo de una crisis sin precedentes ocasionada por la COVID-19, que ha generado una enorme transformación organizativa. Esta crisis ha 
impactado de manera inicial en el ámbito social y de la salud, pero sus efectos han causado una fuerte crisis económica en la mayoría de los países.

Esta pandemia permitió evidenciar de manera explícita problemas asociados a las infraestructuras existentes, a la prestación de servicios básicos, a la garantía de derechos fundamentales como la educación y la salud, tomando en cuenta, por ejemplo, que en el sistema educativo fiscal se tienen 1.039.470 estudiantes -el $35 \%$ del universo total- que no poseerían acceso a Internet en sus hogares, según datos del ente rector. Además, el consumo promedio de un estudiante podría bordear los 2GB por mes.

Ha sido incuestionable la creciente dependencia a estar conectados que hemos experimentado durante este periodo de confinamiento, y eso ha demandado que las empresas prestadoras de servicios busquen mecanismos para satisfacer estas necesidades de conectividad. Sin embargo, todos los esfuerzos se han encaminado a potenciar los servicios en los clientes existentes, pero escasamente se han encaminado a generar infraestructura para atender a los desconectados.

Los lineamientos, programas y políticas constantes en las agendas digitales no han sido suficientes para mitigar o erradicar la brecha digital. Por ello, es una necesidad inminente revisar los marcos normativos, legales y de política pública para que puedan adecuarse innovadoramente en el corto tiempo y permitir la implantación de mecanismos efectivos que posibiliten erradicar la brecha digital.

La problemática asociada a la brecha es realmente grave porque, en el caso de los grupos vulnerables, no solo los priva de acceso a un servicio, sino que los priva de ejercer sus derechos fundamentales, porque la forma tradicional de impartir educación cambió por teleducación; la forma de administrar salud cambió por telemedicina y la forma de trabajar dio un salto al teletrabajo. En el caso de la educación, ha sido por demás evidente el impacto negativo sufrido por los grupos vulnerables que son parte de la brecha digital, pues todo el proceso de formación académica adaptado a la realidad actual está soportado enteramente sobre plataformas de teleducación.

Si se pudiera sacar algún beneficio de la crisis gestada por la pandemia de COVID-19, sería el acrecentamiento de la necesidad de conectarse que ha surgido dentro de todos los grupos sociales y etarios, con fines sociales, laborales o académicos. Sin embargo, no basta con que esa necesidad esté creada pues aún no se han corregido condiciones de accesibilidad, calidad y asequibilidad, lo cual ha impedido cerrar esta brecha durante años.

\section{La brecha digital en Ecuador a nivel nacional y}




\section{desagregado}

Las variables de densidad de servicios móviles y de Internet se encuentran en un crecimiento importante entre 2015 y $2018{ }^{[4]}$; sin embargo, Ecuador se encuentra debajo del promedio de los países de Sudamérica, según datos de la Unión Internacional de Telecomunicaciones (UIT).

Figura 8. Cuentas y densidad de los servicios móviles e Internet
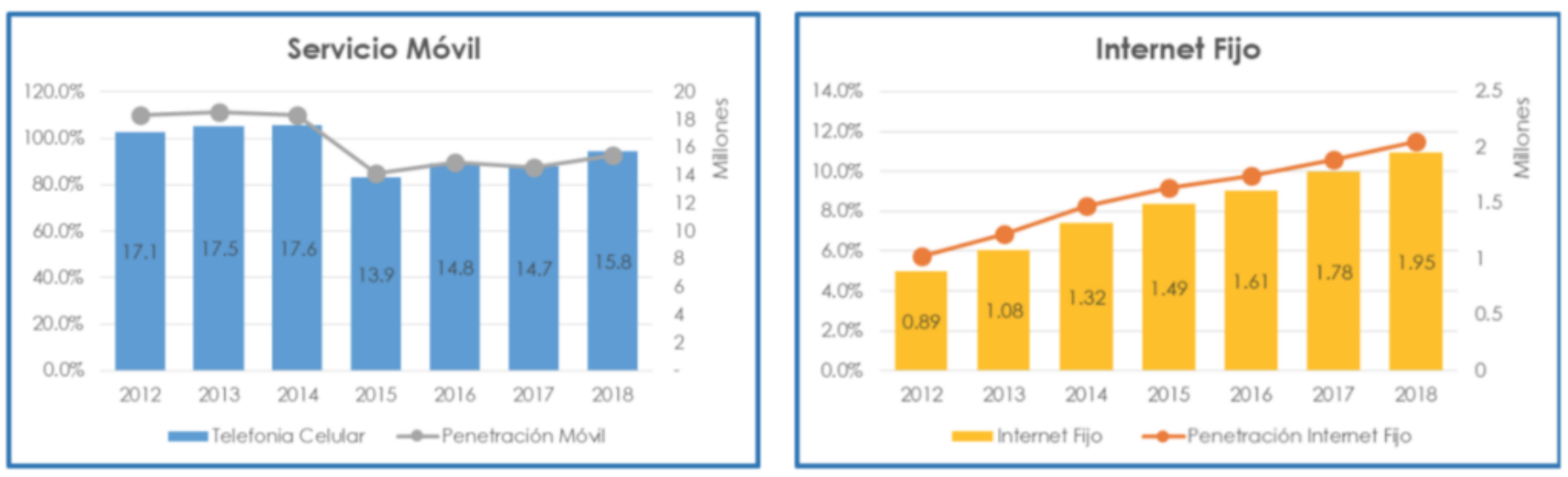

Fuente: ARCOTEL 2012-2018, elaboración propia.

En ese sentido, cabe destacar que, según información del Ministerio de

Telecomunicaciones, para el año 2018, la cobertura del servicio móvil a nivel nacional se encuentra alrededor del $96 \%$ de la población y, con respecto a Internet, en un 83 \% a nivel geográfico. Es decir que la brecha nacional de demanda asciende a $37 \%$, tomando en consideración que el 59 \% de la población mantiene un teléfono celular activo.

Figura 9. Brecha del servicio móvil a nivel nacional 


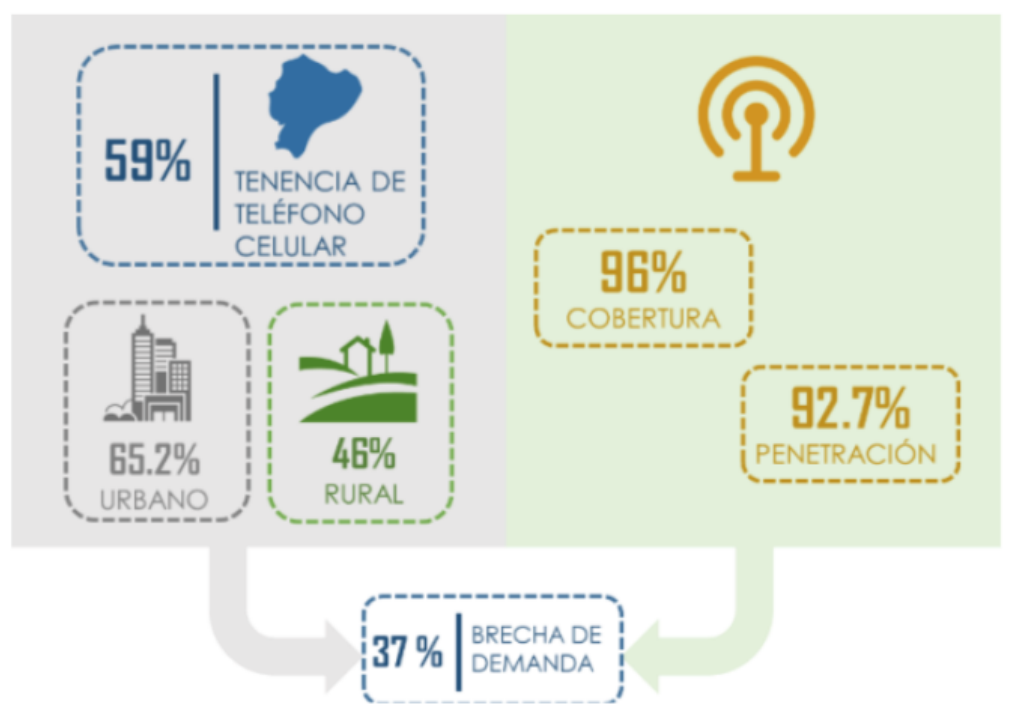

Fuente: INEC, ARCOTEL 2018, elaboración propia.

En cambio, con respecto a Internet, para el año 2018 se puede notar que, en la diferencia entre la usabilidad y el acceso en el hogar, la brecha corresponde a un 11,41\%.

Figura 10. Brecha de Internet a nivel nacional

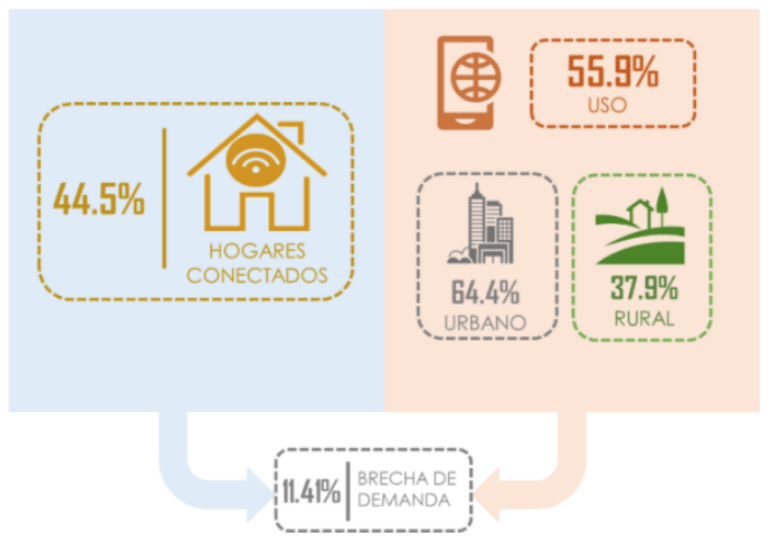

Fuente: INEC, ARCOTEL 2018, elaboración propia.

\subsection{Brecha desagregada a nivel parroquial del acceso móvil}

En los análisis realizados con respecto a los indicadores de brecha de los servicios de telecomunicaciones, se pueden notar dos particularidades:

- A nivel nacional, la brecha móvil y la de Internet han mejorado anualmente debido al crecimiento de los índices de acceso. 
- Con respecto a la categorización geográfica y de género, si bien el acceso muestra un crecimiento principalmente desde 2015, se puede notar una reducción en la brecha de conocimiento y manejo de la TIC.

Así, para complementar la mirada a nivel local (parroquial), se presenta a continuación un análisis aproximado de tendencia sobre la división porcentual de la brecha parroquial, con el objetivo de determinar posteriormente los factores clave que presentan las zonas que poseen una menor desigualdad digital.

Para el análisis, se toma en consideración la encuesta multipropósito TIC 2018, realizada por el INEC, en donde se toma una muestra de 26.928 viviendas, ubicadas en 496 de las 1.024 parroquias, en las cuales se considera una cantidad determinada de observaciones sobre la tenencia de equipamiento móvil y usabilidad de Internet. Por otro lado, en la información presentada por los operadores, en los registros administrativos generados por la ARCOTEL, se puede obtener el nivel de cobertura o de penetración.

De esa forma, la intersección entre la información presentada y calculada ayuda a determinar la distribución porcentual de la brecha con el objetivo de tomar en consideración características que permitan distinguir aspectos relacionados con los mecanismos de conectividad que puedan plantearse.

Los datos mostrados se distribuyen de dos formas: el porcentaje de brecha ordenada de forma descendente por parroquia y la dispersión entre población y brecha.

\subsubsection{Brecha parroquial de servicio móvil}

En las figuras mostradas se puede notar un mayor porcentaje de localidades con brechas superiores al $40 \%$. El 16,35 \% de las parroquias analizadas presentan una brecha menor al $40 \%$, mientras que el 36,49\% posee una brecha mayor al $80 \%$.

Asimismo, la figura de dispersión muestra una concentración con tendencia entre 30 \% y $50 \%$ de brecha a medida que se incrementa la cantidad de habitantes de las localidades. En general, el mayor porcentaje de parroquias que presenta una mayor brecha de acceso se encuentra en localidades con menor número de habitantes, pero esa no es una condición sine qua non para determinar un menor acceso, dado que existe una distribución de parroquias con similar número de personas que poseen una brecha menor incluso que la de localidades más extensas.

Lo que sí podría inferirse es que las parroquias con menor brecha y menor número de habitantes tienen una particularidad: presentan una cercanía con parroquias más grandes y con un nivel de cobertura considerable. Además, se encuentran altamente densificadas en un solo punto geográfico o centro poblado, aunque incluso la cobertura a nivel geográfico no sea del 100 \%. Es decir que una condición influyente para el acceso puede ser la orografía del centro poblado y la cercanía de cobertura en zonas concentradas y 
desarrolladas.

Figura 11. Brecha móvil a nivel parroquial
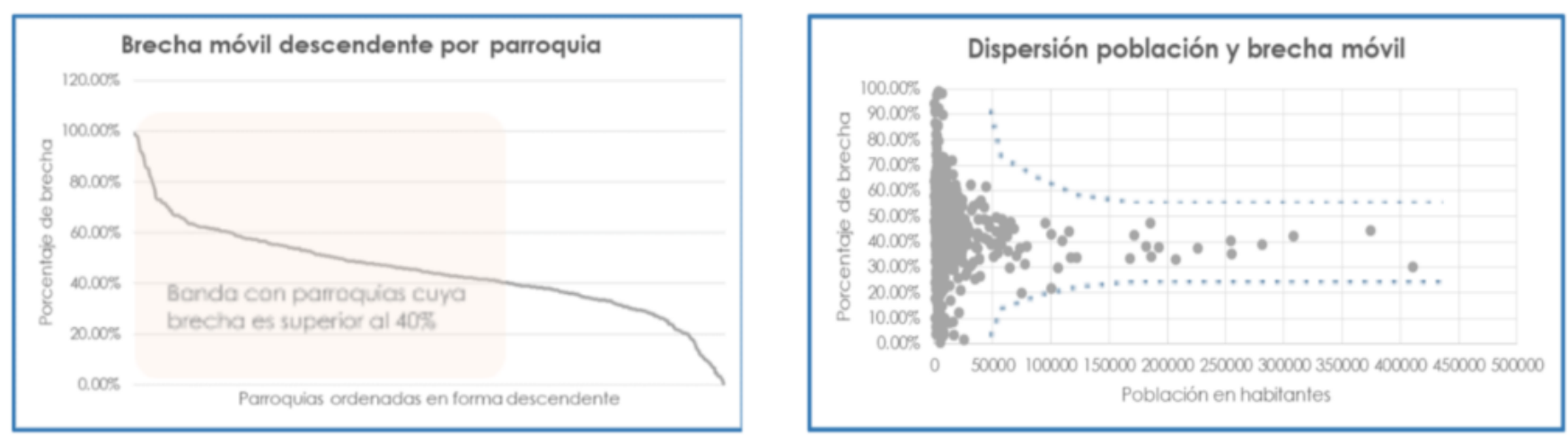

Fuente: INEC 2018, elaboración propia.

La disposición descendente de las parroquias (eje ' $\mathrm{x}$ ') del valor correspondiente a su brecha se puede apreciar en la Tabla 1 que presenta una mayor cantidad de parroquias con una brecha de acceso superior al 60 \% (83,47 \%); para lo cual, a continuación se presenta la distribución de dichas poblaciones dividida en quintiles. También se menciona la cantidad de parroquias que poseen brechas entre $80 \%$ y $100 \%$, un poco más del doble de las que presentan brechas menores al $20 \%$, pero su característica es su inaccesibilidad a nivel geográfico y poca cercanía con un nodo o infraestructura de telecomunicaciones.

Tabla 1. Brecha móvil con distribución porcentual a nivel parroquial

\begin{tabular}{|c||c|}
\hline Porcentaje de brecha & Porcentaje de parroquias \\
\hline \hline $100 \%$ & $6,25 \%$ \\
\hline \hline $80 \%$ & $30,24 \%$ \\
\hline \hline $60 \%$ & $46,98 \%$ \\
\hline \hline $40 \%$ & $13,51 \%$ \\
\hline \hline $20 \%$ & $3,02 \%$ \\
\hline
\end{tabular}


Por otro lado, es importante mencionar que las localidades con brechas entre $40 \%$ y $60 \%$ presentan cercanía geográfica con una cantidad importante de infraestructura que podría ser ocupada para impulsar cobertura y, a su vez, aumentar el acceso a través de su asequibilidad.

\subsubsection{Brecha parroquial de uso de internet}

A continuación, se puede notar que un 95,98 \% de las localidades tienen brecha superior al $40 \%$. Únicamente el 4,02 \% de las parroquias analizadas presentan una brecha menor al $40 \%$, mientras que el $57,75 \%$ posee una brecha mayor al $80 \%$.

Al igual que el análisis en la anterior sección, la figura de dispersión muestra una concentración con una tendencia mayor, entre $30 \%$ y $60 \%$ de brecha, a medida que se incrementa la cantidad de habitantes de las localidades. De la misma forma, el mayor porcentaje de parroquias que presenta una mayor brecha de acceso se encuentra en localidades con menor número de habitantes, pero con la particularidad de que la brecha de uso no llega a niveles como el servicio móvil. ${ }^{[5]}$ En ese sentido, se podría colegir que Internet es un servicio más difundido y más utilizado. Inclusive, la franja de parroquias que se encuentra con una brecha superior al $40 \%$, si bien es mayor en número $(95,98 \%$ ) y más concentrada, la brecha en la mayoría de parroquias es menor que la del servicio móvil.

Por otro lado, las parroquias con mayor brecha y menor número de habitantes tienen una característica puntual: presentan cercanía con un centro de comunicaciones comunitario (infocentro) que podría ser la base para su difusión, pero en otros casos, nuevamente las condiciones orográficas hacen que sea difícil la implementación de soluciones óptimas para desarrollar el servicio.

Figura 12. Brecha de uso de Internet a nivel parroquial
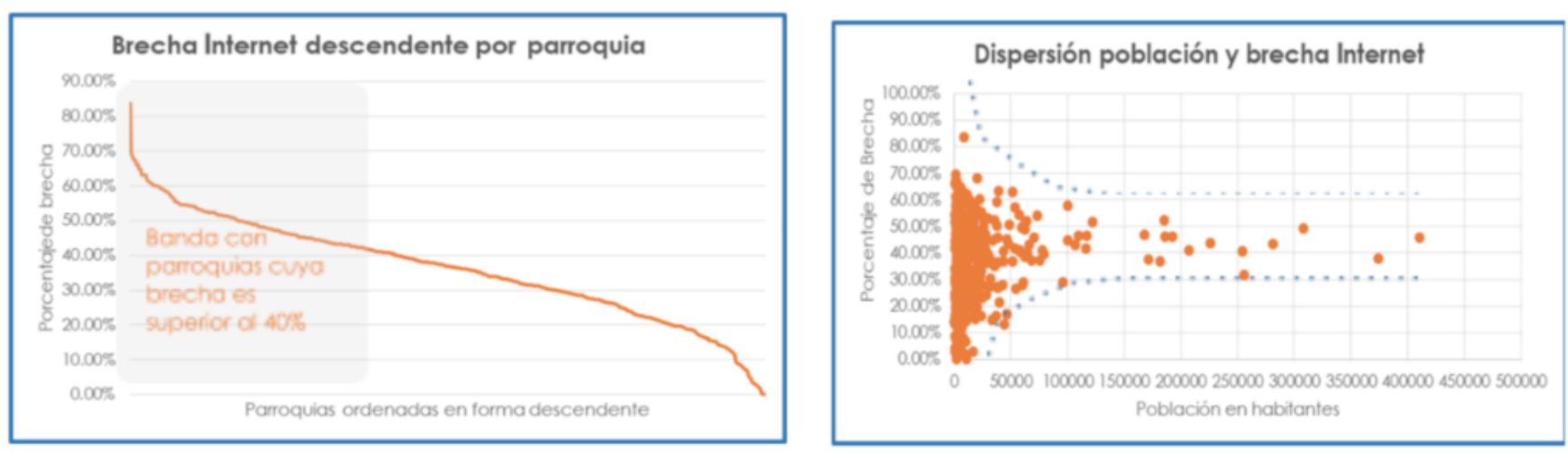

Fuente: INEC 2018, elaboración propia.

La disposición descendente de la brecha de las parroquias se muestra en la Tabla 2 que 
presenta una mayor cantidad de parroquias con una brecha de acceso superior al $60 \%$ (95,98 \%); para lo cual a continuación se presenta la distribución de dichas poblaciones dividida en quintiles. Las parroquias que poseen brechas entre $80 \%$ y $100 \%$ son las que presentan características de inaccesibilidad a nivel geográfico y poca cercanía con un nodo o infraestructura de telecomunicaciones.

Tabla 2. Brecha de uso de Internet con distribución porcentual a nivel parroquial

\begin{tabular}{|c||c|}
\hline Porcentaje de brecha & Porcentaje de parroquias \\
\hline \hline $100 \%$ & $14,69 \%$ \\
\hline \hline $80 \%$ & $43,06 \%$ \\
\hline \hline $60 \%$ & $38,23 \%$ \\
\hline \hline $40 \%$ & $3,82 \%$ \\
\hline \hline $20 \%$ & $0,20 \%$ \\
\hline
\end{tabular}

\section{Análisis de la información y descripción de la metodología}

\subsection{Base de datos}

Con el objetivo de realizar la estimación y analizar la magnitud del indicador que más influye sobre la brecha en determinadas localidades, se utiliza información perteneciente a la Encuesta Multipropósito TIC del INEC, para obtener datos de individuos y hogares para el año 2018. En esta encuesta se dispone de información sobre la tenencia de un teléfono celular activo y usabilidad de Internet. Esta posee datos de 26.928 viviendas y 93.975 individuos distribuidos en 496 parroquias a nivel nacional.

Por otro lado, se utiliza información de los registros administrativos generados por el MINTEL y por ARCOTEL, para obtener datos de cobertura parroquial de la señal móvil y la penetración de los servicios de Internet a nivel parroquial, respectivamente.

\subsection{Metodología y modelo para la estimación}

Para la estimación del modelo se utiliza una regresión multivariante con variables 
dicotómicas, sobre una base de información desbalanceada de 1.024 parroquias, con 496 datos de brecha para las localidades existentes en la encuesta multipropósito. Este modelo relaciona la cobertura móvil y de Internet como variable dependiente y otras métricas observables a nivel parroquial, como el nivel de necesidades básicas insatisfechas, la cantidad de infraestructura emplazada, la categoría geográfica (urbana/rural) y regional, la cantidad de escuelas fiscales y centros de salud, así como nodos e infocentros desplegados en dichas localidades.

Nuestro objetivo es analizar las características de la brecha digital móvil y de Internet para poder analizar las zonas que actualmente no poseen acceso a los servicios. Así, el modelo planteado para la brecha móvil es el siguiente:

$$
\log \left(C S M A_{i}\right)=\beta_{0}+\beta_{1} N B I_{i}+\beta_{2} U R_{i}+\beta_{3} S_{i}+\beta_{4} C_{i}+\beta_{5} B S M A_{i} \quad(E c .1)
$$

En donde:

$\operatorname{CSMA}_{i} \quad$ Cobertura móvil de la parroquia "i"

$N B I_{i} \quad$ Índice de necesidades básicas insatisfechas de la parroquia "i”"

$U R_{i} \quad$ Característica Urbana $=1$ o Rural $=0$ de la parroquia "i"

$S_{i} \quad$ Característica Regional Sierra=1 de la parroquia "i"

$C_{i} \quad$ Característica Regional Costa=1 de la parroquia "i”"

$B S M A_{i} \quad$ Brecha móvil de la parroquia "i"

A continuación, en la Tabla 3, se presenta el resultado del modelo. A partir de él se puede determinar que por cada $10 \%$ de incremento en la brecha de acceso al servicio móvil, la cobertura presenta una ampliación de hasta 27,27 \% en la población. Es decir que cuanto mayor sea la cantidad de cobertura generada, la brecha puede acrecentarse en un $27 \%$, si las condiciones no son las adecuadas para llegar con el acceso efectivo a la población, algo que sin duda podría llamar la atención, dado que la variable de brecha de acceso, a pesar de ser cercanamente significativa, se esperaría que tuviese signo negativo. Eso explicaría de alguna manera que, a medida que aumenta la cobertura, podría ir cerrándose la brecha. Pero, como se explicó inicialmente, la influencia que tiene el aumento de cobertura sobre la brecha dependería del nivel adquisitivo para poder ir reduciéndola y no se fomenta por el lado de la oferta. 
En general, la característica socioeconómica de los habitantes, para poder tener acceso a un plan asequible, es la variable determinante en la cobertura que realizan los operadores, ya que por cada $1 \%$ de incremento en el índice de necesidades básicas, referente al porcentaje de personas no pobres, la cobertura aumenta un 5,99\%.

Tabla 3. Resultado del modelo de cobertura del servicio móvil

\begin{tabular}{|c|c|c|c|c|c|c|}
\hline Source & ss & df & MS & \multirow{2}{*}{\multicolumn{2}{|c|}{$\begin{array}{l}\text { Number of obs } \\
\text { E(5, 477) } \\
\text { Prob }>F\end{array}$}} & \multirow{2}{*}{$\begin{array}{r}483 \\
11.81 \\
0.0000\end{array}$} \\
\hline Model & 12.765081 & 5 & 2.5530162 & & & \\
\hline Residual & 103.086978 & 477 & .216115257 & \multicolumn{2}{|c|}{ R-squared } & 0.1102 \\
\hline Total & 115.852059 & 482 & .240356968 & \multicolumn{2}{|c|}{$\begin{array}{l}\text { Adj R-squared } \\
\text { Root MSE }\end{array}$} & .46488 \\
\hline CSMA & Coef. & Std. Brr. & $t$ & $P>|t|$ & [958 Conf & Interval] \\
\hline NBINoPobres & .5992353 & .143897 & 4.16 & 0.000 & .3164848 & .8819857 \\
\hline UR & .0715883 & .0519839 & 1.38 & 0.169 & -.0305574 & .173734 \\
\hline Sierra & .1907135 & .0531255 & 3.59 & 0.000 & .0863245 & .2951024 \\
\hline Costa & .1996074 & .0595402 & 3.35 & 0.001 & .082614 & .3166008 \\
\hline BrechasMA & .2727799 & .1412515 & 1.93 & 0.054 & -.0047723 & .550332 \\
\hline _cons & 4.016149 & .0826555 & 48.59 & 0.000 & 3.853735 & 4.178563 \\
\hline
\end{tabular}

Cualitativamente, el resultado de los coeficientes indica que el incremento porcentual del índice de necesidades incrementa el nivel de cobertura del servicio móvil, y de igual manera en lo que corresponde a la característica urbana frente a la rural ${ }^{[6]}$. De la misma forma, un sitio regional de sierra o costa es propenso a tener más cobertura que uno de la zona oriental. $^{[7]}$

Para el caso de la cobertura de Internet, el modelo planteado resulta de la siguiente forma: 
En donde:

$$
\log \left(C S A I_{i}\right)=\beta_{0}+\beta_{1} N B I_{i}+\beta_{2} U R_{i}+\beta_{3} S_{i}+\beta_{4} C_{i} \quad(E c .2)
$$

\begin{tabular}{|c|c|}
\hline$C S A I_{i}$ & Uso de Internet de la parroquia "i”" \\
\hline$N B I_{i}$ & Índice de necesidades básicas insatisfechas de la parroquia "i" \\
\hline$U R_{i}$ & Característica Urbana $=1$ o Rural=0 de la parroquia " $\mathrm{i}$ " \\
\hline$S_{i}$ & Característica Regional Sierra=1 de la parroquia "i”" \\
\hline$C_{i}$ & Característica Regional Costa=1 de la parroquia " $\mathrm{i}$ ” \\
\hline$B S A I_{i}$ & Brecha de uso de Internet de la parroquia "i" \\
\hline
\end{tabular}

De la misma manera que en el ejercicio anterior, se puede apreciar en la Tabla 4 que el resultado de los coeficientes muestra que, si existe un incremento porcentual del índice de necesidades, aumenta el nivel de uso de Internet. Se nota el mismo comportamiento en las variables de característica urbana-rural, aunque sin significancia estadística, y de la misma forma en la característica regional de sierra y costa con respecto a la zona oriental. En el caso que se incluye la variable de brecha de uso de Internet, también se presenta un signo positivo y muy alto, lo cual daría a entender que, a medida que aumenta la cobertura de Internet, la brecha más bien tiende a incrementarse, como fue explicado anteriormente, debido a la falta de asequibilidad de las personas.

Así, la interpretación de los índices demuestra que por cada 1 \% de incremento en el índice de necesidades básicas, referente al porcentaje de personas no pobres, la cobertura aumenta un $5,73 \%$.

Por su parte, se puede notar que la influencia de una localidad urbana puede establecer una diferencia de 3,47 \% más de cobertura frente a una parroquia rural. Una localidad de la zona sierra presenta una posibilidad de incremento de cobertura de 9,94 \% y la región costera, de 9,6\% más con relación a cualquier parroquia de la zona oriental.

Tabla 4. Resultado del modelo de cobertura del servicio de Internet 


\begin{tabular}{|c|c|c|c|c|c|c|}
\hline Source & ss & df & MS & Number of obs & $=$ & 497 \\
\hline Model & 127.565585 & 5 & 25.5131171 & Prob $>F$ & $=$ & 0.0000 \\
\hline Residual & 29.7725227 & 491 & .060636502 & R-squared & $=$ & 0.8108 \\
\hline Total & 157.338108 & 496 & 317213928 & Root MSE & $=$ & .24624 \\
\hline
\end{tabular}

\begin{tabular}{r|rrrrrr}
\hline CSAI & Coef. & Std. Err. & $t$ & P $>|t|$ & [958 Conf. Interval] \\
\hline NBINoPobres & .5735662 & .0802881 & 7.14 & 0.000 & .4158156 & .7313168 \\
UR & .0347342 & .0275088 & 1.26 & 0.207 & -.0193153 & .0887837 \\
Sierra & .0994532 & .0276388 & 3.60 & 0.000 & .0451482 & .1537581 \\
Costa & .0965097 & .0307222 & 3.14 & 0.002 & .0361464 & .156873 \\
BrechaSAI & 3.161011 & .0825257 & 38.30 & 0.000 & 2.998864 & 3.323158 \\
_cons & -.0380076 & .0351215 & -1.08 & 0.280 & -.1070146 & .0309994 \\
\hline
\end{tabular}

\section{Oportunidades de expansión}

\subsection{Localidades sin acceso a servicios y priorización}

Con referencia a las metas definidas en algunos planes y estrategias del país, se menciona como una meta lograr el $98 \%$ de cobertura móvil (en términos poblacionales). De igual manera, el análisis de la información de los registros administrativos arroja que 392 parroquias actualmente no poseen cobertura móvil de ningún tipo, mientras que 214 parroquias no poseen servicios móviles ni Internet fijo.

En este sentido, los modelos analizados anteriormente nos determinan que la influencia para tener una expansión de servicios eficiente respondería a un menor nivel de necesidades insatisfechas y, por lo tanto, a un mejor nivel de dotación, en términos de infraestructura (por el lado de la oferta). En consecuencia, se plantea una metodología que incluya como variable dependiente la cantidad de nodos o centros comunitarios para implementar una priorización ordenada de las localidades que podrían empezar a ser cubiertas a través de diferentes mecanismos.

Para alcanzar la cobertura poblacional requerida, se utiliza como referencia el desarrollo de una metodología de priorización de aquellas parroquias estipuladas por el Ministerio de Telecomunicaciones y de la Sociedad de la Información, que considera varios criterios para la puntuación de zonas:

1. Población por parroquia no cubierta con servicio móvil 2G-3G

2. Necesidades básicas insatisfechas - NBI (porcentaje de no pobres) 
3. Escuelas y centros de salud presentes en la zona por cubrir

4. Cantidad de nodos de empresas públicas e infocentros con fibra óptica presentes en la zona por cubrir

La metodología aplicada con los criterios descritos anteriormente plantea un modelo que tiene por hipótesis que, a partir de mayor presencia de nodos ${ }^{[8]}$ e infocentros con fibra óptica en la parroquia por cubrir con servicio móvil, será más rápida la instalación de infraestructura necesaria para alcanzar estos sitios.

El modelo busca describir cómo influye la cantidad de escuelas y centros de salud, así como el porcentaje de "no pobres" medido por el factor de necesidades básicas insatisfechas (NBI) que tiene cada parroquia sobre la cantidad de sitios (nodos e infocentros con fibra), que actualmente están dispuestos en dichas localidades, con la finalidad de cumplir la hipótesis planteada.

El objetivo es llegar a la mayor cantidad de población posible, de manera óptima y eficiente $\mathrm{y}$, de igual manera, que la mayor cantidad de establecimientos educativos y de salud sean cubiertos por la tecnología 2G-3G o soluciones de Internet fijo.

Así, el modelo planteado es el siguiente:

En donde:

$$
(\mathrm{NeI})_{i}=\beta_{0}+\beta_{1} \cdot N B I_{i}+\beta_{2} \cdot E S C_{i}+\beta_{3} \cdot C S_{i} \quad(E c .3)
$$

NeI Número total de nodos e infocentros de una localidad (parroquia)

NBI Índice de necesidades básicas insatisfechas por parroquia (porcentaje de no pobres)

ESC Número de escuelas en la parroquia

CS Número de centros de salud en la parroquia

Como resultado de la regresión, se obtuvieron los siguientes coeficientes.

\section{Tabla 5. Resultado del modelo de priorización de cobertura}

\begin{tabular}{|c|c|c|c|c|c|c|c|c|}
\hline & Grados de libertad & Suma de cuadrados & Promedio de los cuadrados & $F$ & Valor critico de $F$ & & & \\
\hline Regresión & 3 & 94,67224177 & 31,55741392 & 14,2216488 & $8,22701 \mathrm{E}-09$ & & & \\
\hline Residuos & 388 & 860,9604113 & 2,218970132 & & & & & \\
\hline \multirow[t]{2}{*}{ Total } & 391 & 955,6326531 & & & & & & \\
\hline & Coeficientes & Error tipico & Estadisticot & Probabilidad & inferior $95 \%$ & Superior 95\% & Inferior $95,0 \%$ & Superior $95,0 \%$ \\
\hline Intercepción & 0,730582194 & 0,148336808 & 4,925157857 & $1,24981 \mathrm{E}-06$ & 0,438937659 & 1,022226728 & 0,438937659 & 1,0222226728 \\
\hline Variable X1: NBI & 0,04442269 & 0,007626244 & 5,824975969 & $1,20033 E-08$ & 0,029428755 & 0,059416625 & 0,029428755 & 0,059416625 \\
\hline Variable X2: ESCUELAS & 0,023349737 & 0,011389558 & 2,050100314 & 0,041026204 & 0,000956762 & 0,045742712 & 0,000956762 & 0,045742712 \\
\hline Variable $\times 3$ : CS & 0,297192521 & 0,104491667 & 2,844174355 & 0,004688436 & 0,09175178 & 0,502633262 & 0,09175178 & 0,502633262 \\
\hline
\end{tabular}

Como podemos observar, los coeficientes poseen representatividad estadística dentro del 
95 \% de confianza y, al aplicarlos en la base de información disponible, lo que se obtendrá es un valor para cada localidad que responde a las siguientes premisas:

- Por cada nodo e infocentro emplazado dentro de la localidad, se tiene un aumento de 0,0444 de personas no pobres medido sobre el factor de necesidades básicas de la parroquia.

- Por cada nodo e infocentro emplazado dentro de la localidad, se tiene un aumento de escuelas en 0,0233 .

- Por cada nodo e infocentro emplazado dentro de la localidad, se tiene un incremento de 0,2971 en los centros de salud.

En general, la aplicación de los coeficientes determina una puntuación ordenada para cada parroquia, que plantea que una localidad con menores niveles de necesidades, con mayor infraestructura y con mayor número de potenciales beneficiarios, no solo a nivel de hogares, sino en lugares alternativos como escuelas o centros de salud cercanos a la localidad, tiene una mayor probabilidad de ser cubierta.

En resumen, exclusivamente para el caso de las localidades agrupadas, se obtiene una puntuación para cada localidad, y se determinó un conjunto de sitios que podrían ser priorizados por etapas, de acuerdo a la siguiente tabla.

Tabla 6. Tabla de priorización de zonas para cobertura de servicios

\begin{tabular}{|c|c|c|}
\hline Zonas & Valor modelo & Número de parroquia \\
\hline ETAPA 1 & $1,687-3,459$ & $1-118$ \\
\hline ETAPA 2 & $1,251-1,673$ & $119-240$ \\
\hline ETAPA 3 & $0-1,249$ & $241-392$ \\
\hline
\end{tabular}

El planteamiento es que por cada etapa se puedan diseñar diferentes estrategias basadas en lo siguiente:

Etapa 1: inversión a través de empresas públicas o privadas por medio de mecanismos de expansión imputables a incentivos en derechos por licencias o uso de espectro.

Etapa 2: inversión pública en proyectos sociales o diseño de figuras de redes de uso social sin fines de lucro con actores locales (redes comunitarias).

Etapa 3: inversión con fondos de servicio universal en parroquias de difícil acceso y bajos niveles de penetración. 


\subsection{Marco legal y regulatorio para el establecimiento y desarrollo de las redes comunitarias}

Los reguladores sectoriales tienen la misión de revisar y reformar de manera periódica los marcos legales y regulatorios, a fin de que contribuyan a la expansión y al desarrollo del ecosistema digital. Por su parte, la regulación para el desarrollo y masificación de la infraestructura juega un papel importantísimo en la universalidad de los servicios pues, al mismo tiempo que fomenta la expansión de las redes y la inversión en nueva infraestructura, debe lograr también que la infraestructura llegue a las zonas de atención prioritaria o zonas con baja cobertura de servicios, pero no a través de exaltaciones retóricas, sino a través de mecanismos efectivos y eficientes.

Por su parte, los entes hacedores de política pública deben establecer las directrices para que todo el marco legal y normativo se enfoque en la universalización del servicio para ir cerrando la brecha digital. Las políticas públicas recogidas en las agendas digitales o planes de digitalización constituyen un pilar necesario para incrementar la potencialidad de aprovechamiento de las TIC en todos los sectores de la sociedad y para reducir las asimetrías de acceso a los servicios, promoviendo de esta manera, a nivel transversal, la adopción tecnológica y marcando la pauta para el desarrollo de la economía digital. El primer desafío es revisar las leyes que rigen el sector y hacer una transición conceptual y práctica hacia una prestación convergente, universal, innovadora y asequible.

Uno de los aspectos fundamentales para considerar en la revisión de la legislación es el desarrollo y la masificación de infraestructuras, y la expansión de los servicios a toda la población desde la óptica de la accesibilidad y asequibilidad.

En aspectos de regulación secundaria y normativa técnica sectorial, es necesario contar con instrumentos que promuevan la capilaridad y el desarrollo de las infraestructuras, pero no solo desde la óptica comercial, sino desde la óptica social. Es decir, introducir conceptos necesarios para la universalización de servicios, tales como redes comunitarias, operadores rurales de infraestructura u otros similares que, mediante la utilización del espectro radioeléctrico, desarrollen nueva infraestructura de red para el fomento, la apropiación y la provisión de los servicios de telecomunicaciones en zonas que son excluidas de la atención de los operadores establecidos.

Las leyes marco del sector de las telecomunicaciones a nivel mundial se han basado tradicionalmente en la regulación y el control de la prestación de servicios de telecomunicaciones y han abordado la universalización de los servicios, a manera de principios u objetivos. En ningún caso han sido específicas en la aplicación de conceptos o mecanismos tangibles que permitan hacer un cierre efectivo de la brecha digital, sobre todo en los sectores en los que la infraestructura comercial no llega, debido a las condiciones socioeconómicas. 
Adicionalmente, en la región de Latinoamérica y el Caribe, aún existen países que mantienen marcos legales obsoletos y muy poco evolucionados, que han sido aprobados hace al menos una década, y que no tienen ninguna orientación específica a la reducción de asimetrías en acceso a los servicios.

Haciendo una evaluación general y un recuento histórico de las iniciativas (algunas de ellas materializadas en programas) orientadas a disminuir la brecha digital, que han sido implementadas en varios países de la región, haremos referencia a aquellas más difundidas:

1. La primera se relaciona con contribuciones y obligaciones de acceso universal incluidas en las normas o en los títulos habilitantes de los prestadores de servicios, fijando el pago a los Estados de contribuciones periódicas sobre la facturación de sus servicios. Por su parte el Estado asignaba estos recursos a fondos especiales, constituidos para promover el servicio universal. Como complemento a esta iniciativa, se incluyeron también obligaciones de cobertura o planes de expansión, especialmente en los servicios de telecomunicaciones de voz tanto fijos como móviles.

En algunos países esta medida dio mejor resultado que en otros, pues aquellos que realizaron un manejo responsable de los fondos pudieron implementar ciertos programas de conectividad y de acceso a servicios. Sin embargo, muchos de estos programas no fueron sostenidos en el tiempo. Respecto de los planes de expansión, si bien se logró incrementar los sitios conectados a servicios, estos sitios se ubicaban normalmente dentro de las áreas de cobertura de cada operador, con lo cual no cumplieron el objetivo, que era acceder a los sitios donde se quería llegar por la imposibilidad de despliegue de infraestructura.

1. Otra iniciativa implementada a nivel de la mayoría de los países de la región fue el despliegue de centros comunitarios de acceso a la información (telecentros comunitarios o infocentros), que se constituían para el acceso masivo de las poblaciones que no tenían acceso domiciliario a servicios básicos de telecomunicaciones. Estos telecentros en un primer momento resultaron eficientes pues cumplieron su objetivo, que era básicamente reducir el analfabetismo digital y prestar servicio a la población de una determinada comunidad. Sin embargo, muchos de ellos con el paso del tiempo terminaron abandonados, excepto en países donde tenían planes o estrategias para asociar estos centros a programas sociales, de desarrollo educativo, entre otros.

2. La tercera iniciativa, aunque escasamente implementada en la región, fue la asignación de subsidios públicos en servicios de telecomunicaciones para segmentos de la población vulnerable, pero se convirtió en un mecanismo poco sostenible en el tiempo, pues estaba sujeto a la voluntad política de los gobernantes y a la priorización de recursos sobre otro tipo de programas sociales, como salud y educación.

Considerando las lecciones aprendidas de iniciativas pasadas, implementadas para disminuir la brecha digital y maximizar el despliegue de servicios a nivel de todo el territorio, varios países de la región se han involucrado en la gestión y promoción para 
desplegar infraestructura en zonas rurales y han desarrollado marcos regulatorios y normativos que han servido como facilitadores para llevar servicios y cobertura a las zonas no atractivas para los operadores establecidos y han permitido plantear nuevos esquemas asociativos, priorizando la ocupación preferente de los recursos radioeléctricos, y promoviendo ofertas mayoristas que permitan capilarizar la red de los operadores establecidos, por medio de operadores rurales.

En este estudio haremos un análisis del estado del marco legal y regulatorio de Ecuador, con el fin de identificar posibles propuestas de reforma o de complementación normativa, en torno a las alternativas de conectividad, para conseguir que la mayor parte de la población ecuatoriana logre estar conectada en el menor tiempo posible.

\subsection{Entorno regulatorio de las redes comunitarias para Ecuador}

En el caso de Ecuador se promulgó la Ley Orgánica de Telecomunicaciones (LOT) en el año 2015 y su Reglamento General en el año 2016, con lo cual se convierte en la legislación más actualizada de la región. Esta ley cuenta con un articulado bastante desarrollado en aspectos de despliegue de infraestructura de red, prestación de servicios y fomento del acceso universal. Se sustenta sobre varios objetivos que apalancan el establecimiento, el fortalecimiento y el desarrollo de infraestructuras para la masificación de los servicios en todo el territorio nacional. Para este caso, nos referiremos de manera puntual a tres de ellos:

4. Promover y fomentar la convergencia de redes, servicios y equipos.

5. Promover que el país cuente con redes de telecomunicaciones de alta velocidad y capacidad, distribuidas en el territorio nacional, que permitan a la población entre otros servicios, el acceso al servicio de Internet de banda ancha.

6. Establecer las condiciones idóneas para garantizar a los ciudadanos el derecho a acceder a servicios públicos de telecomunicaciones de óptima calidad, con precios y tarifas equitativas y a elegirlos con libertad así como a una información precisa y no engañosa sobre su contenido y características.

En aras de garantizar a todos los ciudadanos el acceso igualitario y no discriminatorio a los servicios y favorecer el desarrollo del servicio universal, la LOT prevé la posibilidad de regular tarifas preferenciales para favorecer el desarrollo económico de regiones y grupos sociales de atención prioritaria.

La LOT, a diferencia de su antecesora (la Ley Especial de Telecomunicaciones), contiene un capítulo referente a la promoción de la sociedad de la información y del conocimiento y al rol del Estado en la promoción de la prestación del servicio universal, siendo relevantes, entre otros, los siguientes aspectos:

- Promover el acceso universal a los servicios de telecomunicaciones en todo el territorio, con el fin de asegurar una adecuada cobertura de los servicios.

- Elaborar un Plan Nacional de Servicio Universal de atención prioritaria a las áreas 
geográficas de menos ingresos y con menor cobertura de servicios en el territorio nacional.

- Ejecución de proyectos y programas de servicio universal.

- Contribución económica de los prestadores de servicios de telecomunicaciones con el $1 \%$ de los ingresos totales facturados y percibidos.

Asimismo, se establecen tres tipos de títulos habilitantes para el uso del espectro radioeléctrico: concesiones, autorizaciones y registro de servicios.

- Las concesiones son para servicios tales como telefonía fija y servicio móvil avanzado, así como para el uso y explotación del espectro radioeléctrico, por empresas de economía mixta, por la iniciativa privada y la economía popular y solidaria.

- La autorización es para el uso y explotación del espectro radioeléctrico por las empresas públicas e instituciones del Estado.

- Registro de servicios para los siguientes servicios: portadores, telecomunicaciones móviles por satélite, cable submarino, valor agregado, acceso a Internet, troncalizados, comunales y otros que determine el Directorio de la ARCOTEL, previo informe de la Dirección Ejecutiva de la ARCOTEL, de conformidad con el ordenamiento jurídico vigente.

Por su parte, el acuerdo ministerial 15-2019 de 18 de julio de 2019, establece:

4.6 Conectividad. Masificar y ampliar la cobertura de servicios de telecomunicaciones y la migración a redes de nueva generación y de alta velocidad, a través de los siguientes objetivos: Estimular el despliegue de redes comunitarias de internet sin fines de lucro, para beneficiar a 127 mil hogares que podrán acceder al servicio con tarifas reducidas.

El Plan Nacional de Frecuencias, por su parte, dentro de la categoría de los servicios y las atribuciones establece:

\subsubsection{Servicios primarios y secundarios}

3) Las estaciones de un servicio secundario:

1. a) no deben causar interferencia perjudicial a las estaciones de un servicio primario a las que se les hayan asignado frecuencias con anterioridad o se les puedan asignar en el futuro;

2. b) no pueden reclamar protección contra interferencias perjudiciales causadas por estaciones de un servicio primario a las que se les hayan asignado frecuencias con anterioridad o se les puedan asignar en el futuro;

3. c) pero tienen derecho a la protección contra interferencias perjudiciales causadas por estaciones del mismo servicio o de otros servicios secundarios a las que se les asignen frecuencias ulteriormente.

El Código de Ingenios en su artículo 40 establece: 
El Estado garantizará el acceso universal al servicio público de internet en los términos previstos en la Constitución de la República. Los organismos competentes vigilarán que el precio de este servicio sea equitativo, y establecerán los mecanismos de control y regulación correspondientes (...)

(...) Los gobiernos autónomos descentralizados deberán poner a disposición libre y gratuita de la ciudadanía, acceso a internet inalámbrico en los espacios públicos de concurrencia masiva destinados al ocio y entretenimiento, de acuerdo a las condiciones que establezca el reglamento correspondiente.

Además, en Ecuador existe la Norma Técnica para Uso Compartido de Infraestructura Física de los Servicios del Régimen General de Telecomunicaciones, que estipula que todo poseedor de título habilitante tiene la obligación de compartir su infraestructura física, excepto cuando existan circunstancias técnicas que impidan dicho uso.

En el país se han realizado proyectos piloto con uso de nuevas tecnologías para conectividad en zonas rurales. Sin embargo, no existe un marco específico para la operación de redes rurales o redes comunitarias que cuenten con excepciones o salvedades para acceso preferente a espectro radioeléctrico o que tengan un marco favorable para su despliegue masivo.

En el caso de Ecuador, si bien existe el título habilitante para servicio de acceso a Internet, hay que considerar el esquema de última milla y las cargas regulatorias asociadas a este título, lo cual encarece el despliegue de la redes comunitarias. Adicionalmente, existe norma expresa para el uso compartido de infraestructura de proveedores de servicios que poseen títulos habilitantes, lo cual da la oportunidad de que cualquier asociación o cooperativa que tenga un título habilitante pueda solicitar acceso a infraestructura de otro proveedor, o si fuera el caso de no llegar a un acuerdo entre las partes, la normativa señala que la ARCOTEL pueda disponer el uso compartido mientras no existan circunstancias técnicas que lo impidan.

A continuación se presenta un resumen de todas las acciones regulatorias tendientes a facilitar un marco de desarrollo para las redes comunitarias en la región, con el objetivo de validar qué permite cada legislación en torno al despliegue de las redes en zonas rurales, lo cual permitirá contextualizar una alternativa para hacerla viable en Ecuador.

Tabla 7. Benchmarking de características regulatorias para el fomento de redes comunitarias 


\begin{tabular}{|c|c|c|c|c|c|c|}
\hline & $\begin{array}{l}\text { Red } \\
\text { propia }\end{array}$ & $\begin{array}{l}\text { Compartición } \\
\text { infraestructura }\end{array}$ & $\begin{array}{l}\text { Operador } \\
\text { con TH } \\
\text { diferente }\end{array}$ & Exenciones & $\begin{array}{l}\text { Licencia } \\
\text { específicas } \\
\text { para zonas } \\
\text { rurales }\end{array}$ & $\begin{array}{l}\text { Uso } \\
\text { secundario } \\
\text { del } \\
\text { espectro o } \\
\text { espectro } \\
\text { disponible } \\
\text { para redes } \\
\text { rurales }\end{array}$ \\
\hline México & $\bullet$ & $\bullet$ & • & • & - & \\
\hline Perú & • & & - & • & $\bullet$ & $\bullet$ \\
\hline Brasil & $\bullet$ & & & • & & - \\
\hline Argentina & - & - & - & - & - & \\
\hline Colombia & - & - & & - & & \\
\hline Ecuador & - & - & & & & \\
\hline
\end{tabular}

5.5. Propuestas para adecuación normativa vigente en Ecuador para operación de las redes comunitarias

Para la instrumentación y el despliegue afectivo de las redes comunitarias en el país, es necesario hacer una revisión completa de todo el marco legal y de regulación secundaria, con el fin de generar un ecosistema favorable para el desarrollo de estas iniciativas sociales. Las modificaciones deberían partir de la Ley Orgánica de Telecomunicaciones, pues resulta primordial incluir a nivel legal conceptos que reafirmen la naturaleza y la estructura de las redes comunitarias para que, desde ahí, pueda desarrollarse todo el paraguas normativo que apalanque la operación y el despliegue de estas redes, tanto en la parte de desarrollo de infraestructura como en el uso de espectro radioeléctrico y procesos administrativos asociados a dicha operación.

Se citan a continuación aspectos generales que deben ser revisados en la legislación y normativa vigente:

- Definir y categorizar el concepto de redes comunitarias y operadores rurales.

- Revisar el marco de compartición de infraestructura.

- Revisar el marco conceptual para la asignación del espectro radioeléctrico y uso compartido de este.

- Revisar cargas regulatorias asociadas a los títulos habilitantes que permitan apalancar la operación de redes comunitarias u operadores rurales. 
- Revisar mecanismos de financiamiento a través del fondo de servicio universal.

Se han planteado de manera general los lineamientos que ameritan una revisión exhaustiva por parte del ente regulador (ARCOTEL) y el ente rector de la política pública (MINTEL) a fin de establecer un esquema completo que favorezca la introducción de estas alternativas de carácter social. Esto contribuirá a la disminución de la brecha digital y a maximizar la cobertura de redes y prestación de servicios en zonas de atención prioritaria, que por su geografía y realidad socioeconómica han sido históricamente relegadas. En el siguiente cuadro se realizará una caracterización específica de la legislación y normativa que debe ser revisada con las recomendaciones pertinentes.

Tabla 8. Revisión regulatoria ecuatoriana para el fomento de redes comunitarias 


\begin{tabular}{|c|c|c|c|}
\hline $\begin{array}{l}\text { LEY, } \\
\text { REGLAMENTO, NORMA }\end{array}$ & MODIFICACIÓN & COMPLEMENTACIÓN & PROPUESTA SUGERIDA \\
\hline LEY ORGÁNICA DE TELECOMUNICACIONES & Sí & SÍ & $\begin{array}{l}\text { - Introducir concepto de red comunitaria y operador rural. } \\
\text { - Incluir la figura de concesiones de uso social comunitario con } \\
\text { diferencias en pagos y obligaciones. } \\
\text { - Promover asignación de bandas específicas para servicios de uso social, } \\
\text { con diferencias en pagos por uso, pagos por asignación y obligaciones. } \\
\text { - Incluir aspectos de compartición de infraestructura que faciliten el } \\
\text { despliegue de redes comunitarias y operadores rurales. }\end{array}$ \\
\hline $\begin{array}{l}\text { REGLAMENTO GENERAL DE LA LEY ORGÁNICA DE } \\
\text { TELECOMUNICACIONES }\end{array}$ & SÍ & Sí & $\begin{array}{l}\text { - Desarrollo de todos los puntos introducidos en la LOT y mencionados en } \\
\text { el párrafo anterior. }\end{array}$ \\
\hline $\begin{array}{l}\text { REGLAMENTO PARA OTORGAR TÍTULOS } \\
\text { HABILITANTES PARA SERVICIOS DEL RÉGIMEN } \\
\text { GENERAL DE TELECOMUNICACIONES Y } \\
\text { FRECUENCIAS DEL ESPECTRO RADIOELÉCTRICO }\end{array}$ & Sí & Sí & $\begin{array}{l}\text { - Desarrollo de todos los puntos introducidos en la LOT y su Reglamento. } \\
\text { - Crear la ficha para el registro de redes comunitarias. } \\
\text { - Crear la ficha para operador de infraestructura móvil rural. } \\
\text { - Revisar la excepción del pago por derechos de otorgamiento. } \\
\text { - Deben cubrir zonas de interés social y de prioridad, donde exista poco o } \\
\text { nulo despliegue de servicios e infraestructura. } \\
\text { - No tendrán fines de lucro. Su objetivo será dotar de servicios } \\
\text { autoprovisionados a sus habitantes o miembros. } \\
\text { - Para facilitar la conectividad de las redes comunitarias a redes de } \\
\text { transporte y acceso, se podrá considerar planes de expansión de los } \\
\text { prestadores de servicios en puntos específicos cercanos al área de } \\
\text { autoprovisión de las redes comunitarias. }\end{array}$ \\
\hline $\begin{array}{l}\text { REGLAMENTO PARA LA PRESTACIÓN DE SERVICIOS } \\
\text { DE TELECOMUNICACIONES Y SERVICIOS DE } \\
\text { RADIODIFUSIÓN POR SUSCRIPCIÓN }\end{array}$ & Sí & SÍ & $\begin{array}{l}\text { - Crear el régimen de operación de las redes comunitarias. } \\
\text { - Crear el régimen de los Operadores de Infraestructura Móvil Rural } \\
\text { (OIMR). Se sugiere que sea en el entorno de brindar facilidades de } \\
\text { transporte en áreas rurales o lugares de preferente interés social, donde } \\
\text { ningún operador cuente con infraestructura de red propia operativa, que } \\
\text { no tendrá usuarios finales, ni numeración propia. } \\
\text { - Definir el ámbito de operación de los OIMR, así como aspectos de } \\
\text { facilidades de red y compartición de infraestructura. } \\
\text { - Revisar la posibilidad de definir un régimen de calidad de servicios } \\
\text { diferenciado. } \\
\text { - Considerar la exoneración de cargas regulatorias y económicas en } \\
\text { función de lo que determine la LOT. } \\
\text { - Revisión del uso compartido de frecuencias en zonas de interés social. } \\
\text { - Otros aspectos necesarios para la adecuada operación de las redes } \\
\text { comunitarias y OIMR. }\end{array}$ \\
\hline $\begin{array}{l}\text { REGLAMENTO DE DERECHOS POR CONCESIÓN Y } \\
\text { TARIFAS POR USO DE FRECUENCIAS DEL ESPECTRO } \\
\text { RADIOELEECTRICO }\end{array}$ & SÍ & & $\begin{array}{l}\text { - Incluir un régimen que incentive el despliegue de infraestructura con } \\
\text { incentivos en zonas prioritarias o poblaciones vulnerables que estén } \\
\text { desatendidas. Este régimen deberá aplicarse a redes comunitarias y a } \\
\text { operadores que inviertan en dichas zonas. } \\
\text { - Se sugiere que los pagos por uso y asignación de espectro se ciñan a } \\
\text { costos administrativos de gestión del regulador. }\end{array}$ \\
\hline PLAN NACIONAL DE FRECUENCIAS (PNF) & Sí & sí & $\begin{array}{l}\text { - Servicios secundarios en bandas determinadas. } \\
\text { - Uso compartido de frecuencias en zonas de interés social. } \\
\text { - Bandas de frecuencias para operadores comunitarios o de índole social. }\end{array}$ \\
\hline $\begin{array}{l}\text { NORMATIVA DE HOMOLOGACIÓN } \\
\text { NORMATIVA DE CALIDAD } \\
\text { NORMATIVA DE COMPARTICIÓN DE } \\
\text { INFRAESTRUCTURA }\end{array}$ & & sí & $\begin{array}{l}\text { - Revisión de aspectos que promuevan el desarrollo de redes } \\
\text { comunitarias, de manera especial en simplificación de procesos } \\
\text { administrativos y posibles cargas regulatorias. } \\
\text { - Revisar posible aplicación de regulación asimétrica para fomentar } \\
\text { despliegue de infraestructura en zonas de atención prioritaria. }\end{array}$ \\
\hline
\end{tabular}

\section{Conclusiones}

En el análisis de brecha existente en Ecuador, se observan varios componentes, que principalmente se resumen en aspectos de acceso, asequibilidad y área geográfica. La priorización de zonas para atención en función de infraestructura comunitaria o de tipo social existente, como infocentro o escuelas conectadas, permitiría una expansión de red y servicio en todas las localidades priorizadas.

En aspectos de regulación secundaria y normativa técnica sectorial de Ecuador, es necesario contar con instrumentos que promuevan la capilaridad y el desarrollo de las infraestructuras, pero no solo desde la óptica comercial, sino desde la óptica social. Es decir, introducir conceptos necesarios para la universalización de servicios, tales como redes comunitarias, operadores rurales de infraestructura u otros similares que, mediante la 
utilización del espectro radioeléctrico, desarrollen nueva infraestructura de red para el fomento, la apropiación y la provisión de los servicios de telecomunicaciones, en zonas que son excluidas de la atención de los operadores establecidos.

La implementación de redes comunitarias en Ecuador constituye una alternativa viable, que permitirá cumplir con los objetivos de la universalización de los servicios y contribuirá de manera directa a la reducción de la brecha digital a nivel nacional. El Plan de Servicio Universal estableció como política pública el desarrollo y despliegue de redes comunitarias para reducir el índice de analfabetismo digital y promover el uso de las TIC en áreas desentendidas, donde el nivel de accesibilidad y asequibilidad a los servicios de telecomunicaciones son nulas o deficientes.

Sobre la base de las experiencias gestionadas en la región y las lecciones aprendidas respecto de la construcción del entorno adecuado para el desarrollo de las redes comunitarias, hemos propuesto acciones regulatorias concretas, que constituyen el punto de partida para impulsar el despliegue de este ecosistema en Ecuador. Por ello es imperante actualizar el marco regulatorio vigente, considerando principalmente temas de habilitación, condiciones de operación, facilidades de acceso a infraestructura y recursos (espectro radioeléctrico), cargas regulatorias, entre otras.

La responsabilidad de cerrar la brecha debe ser compartida por los Gobiernos y el sector público. Deben facilitarse las condiciones para la implantación de nuevas modalidades para conectarse, para desplegar nueva infraestructura, prestar nuevos servicios y estimular la inversión en zonas prioritarias. El sector privado debe considerar en sus planes empresariales, como un principio, la inclusión y la simetría de acceso en sus estrategias de negocio.

Finalmente, en el contexto de la actual pandemia mundial, uno de los aspectos más importantes que nos dejará esta crisis será la prioridad a corto plazo de gestionar e implementar mecanismos eficaces para cerrar la brecha digital, lo cual es una necesidad imperante para adaptarse al cambio global en la nueva forma de vivir, socializar, estudiar y trabajar.

\section{Referencias bibliográficas}

- Acuerdo Ministerial 15-2019. MINTEL 2019. Obtenido de MINTEL. https://bit.ly/3eaLzUC

- ARCOTEL. 2017. Plan Nacional de Frecuencias. Quito.

- BID. 2019. El impacto de la infraestructura digital en los Objetivos de Desarrollo Sostenible. Washington.

- Castells, Manuel. 2006. La Sociedad Red: Una Visión Global. Madrid: Alianza.

- Código Social de los Conocimientos -Código Ingenios- 2016. SENESCYT 2016. Obtenido 
de SENESCYT. https://bit.ly/2Y5mapU

- Ley Orgánica de Telecomunicaciones. MINTEL 2015. Obtenido de MINTEL. https://bit.ly/3fwPpHW

- Norma Técnica para Uso Compartido de Infraestructura Física de los Servicios del Régimen General de Telecomunicaciones. ARCOTEL 2017. Obtenido de ARCOTEL. https://bit.ly/2BgFes6

- Plan Nacional de Frecuencias 2017. ARCOTEL 2017. Obtenido de ARCOTEL. https://bit.ly/3dd3CYV

- UIT. 2010. UIT-D 19. Obtenido de Telecomunicaciones para las zonas rurales y distantes. https://www.itu.int/dms_pubrec/itu-d/rec/d/D-REC-D.19-201003-I!!PDF-S.pdf

- UIT. 2014. UIT-D 20. Obtenido de Iniciativas de política y reglamentación para el desarrollo de las telecomunicaciones/TIC/banda ancha en zonas rurales y distantes. https://www.itu.int/dms_pubrec/itu-d/rec/d/D-REC-D.20-201404-I!!PDF-S.pdf

- Valencia, Ramiro. 2017. CPR - Vol.12. Impacto de la penetración de las telecomunicaciones en la pobreza y desigualdad en el Ecuador (2009-2010 / 2015-2016): Análisis y planteamiento de políticas para mejorar la cobertura y asequibilidad. Varadero.

\section{Biografía de los Autores}

Ana Valdiviezo Black: Ingeniera en Electrónica con especialidad en Redes y Comunicación de Datos, egresada de maestría en Redes de Información y Conectividad. Cursa la maestría en Big Data y Business Intelligence. Posee más de 18 años de experiencia en la realización de política y regulación del sector de telecomunicaciones en Ecuador y España (CMT). Ha ocupado cargos de Coordinadora de Regulación, Coordinadora de Control en ARCOTEL, Subsecretaria de Telecomunicaciones y TIC, Directora de Telecomunicaciones y Servicios Postales, Viceministra de TIC en MINTEL, Coordinadora Nacional del Consejo Nacional de Telecomunicaciones, Presidenta del Consejo Nacional de Telecomunicaciones (delegación) en el CONATEL.

Ramiro Valencia: Ingeniero en Electrónica y Telecomunicaciones, especialista en Automatización y Control Electrónico, máster en Economía del Desarrollo. Ha trabajado desde hace 10 años en la realización de política y regulación del sector de telecomunicaciones en Ecuador. Se desempeñó anteriormente como director de Planificación de las Telecomunicaciones; director de Estudios, Análisis Estadístico y de Mercado de la Agencia de Regulación y Control de las Telecomunicaciones de Ecuador, ARCOTEL; director de Políticas de Telecomunicaciones y TIC, MINTEL. 


\section{Notas}

$\uparrow 1$ parroquia.

La brecha también existe por el lado de la oferta, pero si no existe una masa crítica $\uparrow 2$ para el consumo, este último termina siendo la variable de control más importante al momento de incrementar los índices de penetración.

Proyectos de alistamiento digital y capacitaciones en infocentros y aulas móviles

$\uparrow 3$ https://infocentros.mintel.gob.ec/estadisticas-infocentros/.

$\uparrow 4$

La tasa de crecimiento compuesta entre 2015 y 2018 en telefonía celular es de 4,41 $\%$ y, de Internet, de $9,43 \%$.

$\uparrow 5$

En el servicio móvil se encontraron localidades con brecha del $100 \%$, mientras que en Internet la brecha de uso más alta se encuentra alrededor del $85 \%$

Se puede notar que la influencia de una localidad urbana puede establecer una diferencia de $7,15 \%$ más de cobertura frente a una parroquia rural.

La sierra presenta una posibilidad de incremento de cobertura de 19,07 \%, y la $\uparrow 7$ región costera de 19,9 \% más, con relación a cualquier parroquia de la zona oriental.

Nodos de empresas públicas CNT EP y CELEC EP. 